\title{
Use of smartphone accelerometers for winter road maintenance improvement in urban areas
}

\author{
K. K. Kaare ${ }^{1}$, O. Koppel ${ }^{1}$ \& K. Kuhi ${ }^{2}$ \\ ${ }^{1}$ Department of Logistics and Transport, \\ Tallinn University of Technology, Estonia \\ ${ }^{2}$ Ericsson Estonia, Ltd., Estonia
}

\begin{abstract}
The objective of the winter maintenance is to maintain transport links and enable everyday life to continue during adverse weather conditions. In urban areas in northern regions, especially with large population and numerous streets the topic to increase efficiency is an important agenda for local authorities. The issues of safety, environmental and health impacts, street availability and minimum delays to the travelling public on the treated network need to be addressed and improvement measures to be taken. This paper investigates an application of participatory mobile sensing with smartphone tri-axial accelerometers: detecting and reporting the surface conditions of roads. The proposed solution is an elaboration of mobile pothole detection using sensor networks for road surface condition monitoring when snow and ice occurs.

Keywords: traffic safety, road maintenance, accelerometers, mobile sensing, participatory sensing.
\end{abstract}

\section{Introduction}

Controlling snow and ice buildup on streets during winter weather events presents several challenges for local road authorities in northern countries. Transportation problems carry severe costs to society - streets covered with ice and snow are slippery and inherently less safe for driving. Furthermore, the number of accidents always increases during and just after winter storms (see Figure 1). Increased competitiveness requires predictable and regular transit times without delays. Effective and comprehensive winter maintenance is costly 
and as it is financed by local governments frequently pressured subject for budget cuts.

Besides snow ploughing the most common way of dealing with ice and snow is to apply salt or abrasives. However salt can cause significant damage to pavements, cars and environment therefore it is important to have information about areas in need of maintenance. Safety concerns provide a major stimulus to improvements in winter street maintenance. Considered together these forces make it highly appropriate to study new methods to improve winter road maintenance planning.

Good analysis and decision making in the transportation industry is often restricted by a lack of adequate information. Costly data collection procedures mean infrequent sampling and delays in maintenance works. Cost considerations and easy access contribute to the wide use of free weather information sources. However, these sources may have problems with timeliness and a lack of detail, which may result in the use of inaccurate weather information.

The most widely used weather information sources for winter maintenance personnel are the free National Weather Service (NWS), private-sector weather providers, and the Road Weather Information System (RWIS). Survey results showed that maintenance personnel relied less on forecast weather parameters than information on current conditions [2].

The optimal distribution of resources for winter street maintenance is possible providing the availability of comprehensive and objective real time data about the state of the streets.Using mobile smartphones makes a substantial set of precise sensors readily available. This provides without significant extra cost reliable and exact information, with extensive coverage. This kind of a solution where citizens contribute to collecting data about the environment has been called participatory sensing [3]. Participatory sensing using smartphone accelerometers as an approach for data collection is proposed in this paper due to its low cost, the large number of road users and large real time coverage.

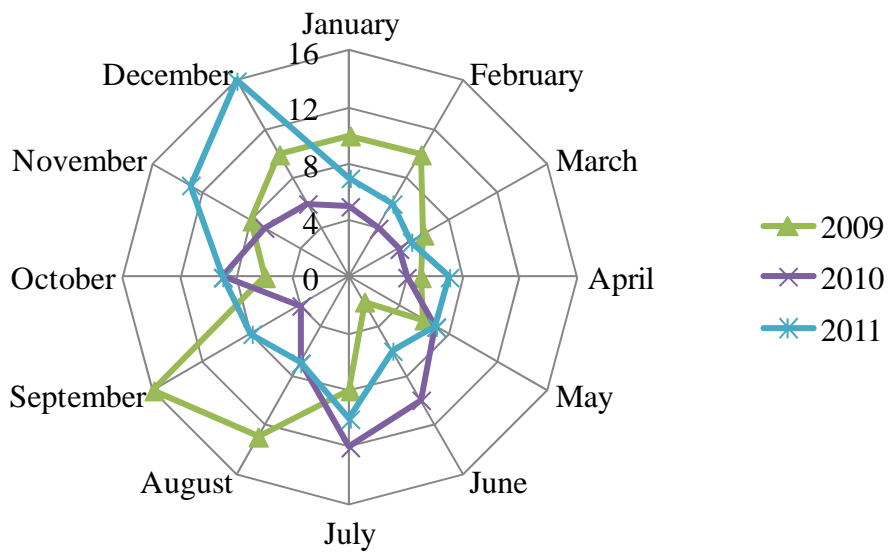

Figure 1: $\quad$ Life-cycle of accidents with fatal consequences in Estonia [1]. 


\section{Related research}

Due to the increasing demand of the transportation authorities for rapid, accurate data acquisition about the road pavement, a mobile mapping system has been developed primarily for road surface detection. As mentioned by Paterson and Watanatada already in 1985[4] here is very clear correlation between vehicle speed, ride quality and road roughness. Road roughness is measured in different ways, using The International Road Roughness Index (IRI) as an indicator to describe it.

IRI is essentially a computer based virtual response type system that summarizes the roughness qualities, that impact vehicle response and is most appropriate when a roughness measure is desired that relates to overall vehicle operating cost, overall ride quality, dynamic wheel loads and overall surface condition. The IRI measurement has $\mathrm{m} / \mathrm{km}$ (sometimes $\mathrm{mm} / \mathrm{m}$ ) or in $/ \mathrm{mi}$ units. The determination of IRI can be easily done from the intersected surface points; only the longitudinal profile has to be used [5].

Within the transportation technology industry, there has been an increasing interest in road surface monitoring and in finding easier ways to map and monitor potholes. The current state-of-the-art in industry is to measure road surface quality using a Falling Weight Deflectometer (FWD). These devices apply a fixed load to the road surface and measure the distortion of the road to that load, giving an estimate of how imminent road surface failures are [6].

Road conditions are naturally sensed from a moving entity that can measure vibrations and impulses during a drive.There are several vehicular sensing systems for pothole and roughness detection, particularly [5-11]:

- BusNet system developed at University of Colombo;

- Tri-axis accelerometers in an embedded Pothole Patrol system together with GPS receivers developed at Massachusetts Institute of Technology;

- Mobile devices as a surrogate traffic sensing and communication systems like Nericell and TrafficSense developed at Microsoft Research India;

- A system developed at National Taiwan University what is using motorcycle-based mobile phones;

- A pothole detection approach in the context of offline data mining, proposed at University of Jyväskylä (Finland);

- A mobile sensing system for road irregularity detection using Android OS based smart-phones developed at University of Latvia;

- $\quad$ Photogrammetry Based Road Roughness Measurement System developed at Budapest University of Technology and Economics (Hungary);

- $\quad$ Different laser scanners.

All the abovementioned solutions focus on finding a cost effective way to detect road surface irregularities but are not designe to take into account winter weather peculiarities in the north and ways to improve safety and effeciency with the same devices and software platforms. An increasing demand for a safe drive during all seasons on various road hazards becomes an important element in ITS (Intelligent Transportation System) platform [12]. 
Accelerometers have been used for a variety of uses throughout the world today, from medical to research, from car performance to robotics. However, with the advent of the iPhone and Android, accelerometers are much more commonplace in the world of today.

\section{Weather information and winter maintenance decisions}

The local governments are responsibility to guarantee good quality transportation infrastructure in urban areas. The task is carried out by urban road authorities who are obliged to make effective maintenance decisions. Controlling snow and ice buildup on streets during winter weather events presents several challenges for them in northern countries (see Figure 2). Treatment types, timing, rates, and locations are decisions that have a considerable impact on roads safety and efficiency. Additionally, poor decisions can have adverse economic and environmental consequences.

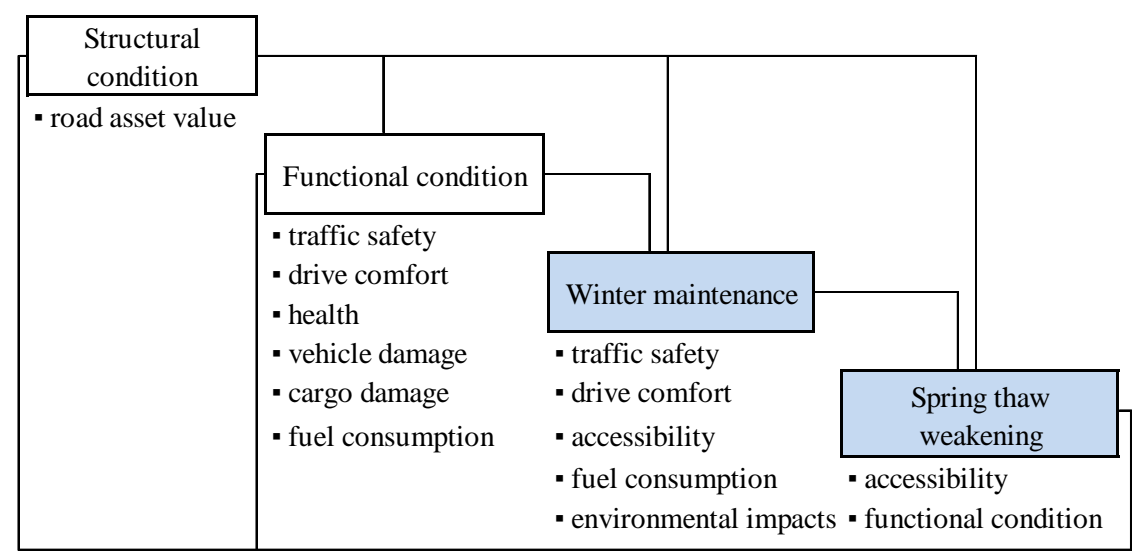

Figure 2: $\quad$ Northern region road condition management areas and their internal relationships for local road authorities [13].

Estonia, for example, is situated on the coasts of the Baltic Sea, being geographically situated in a region where during mild winters there can be several freeze thaw cycles per day. The long coastline supports temperature and humidity changes in very short distances complicate and diverse to manage road maintenance. Road maintenance agencies need real time information about weather conditions and conditions on the roads [14].

To ensure efficient and safe use of roads in winter, snow ploughing is carried out and primarily road salt (sodium-chloride) is used to melt snow and ice, and in some places sand to provide traction for vehicular traffic. The environmental impact of salt and sand use has been widely discussed, but their application is effective, convenient, and inexpensive. To create a balance between safety and 
environmental protection, it is necessary to use a variety of strategies to enhance winter road maintenance, including improving operational practices, implementing new technologies, and using state-of-the-art equipment.

The most noticeable benefit of using weather information for winter maintenance is reducing maintenance cost. Weather information is important in supporting a variety of winter maintenance operations; however, respondents reported needing more weather information to support anti-icing and ploughing/de-icing than to support sanding/grit operations.

Together, these findings suggest that the demand for weather information among winter maintenance personnel will increase in the future. Air temperature, wind, and the type and amount of precipitation are primary parameters of current and forecast weather conditions. Road weather elements such as pavement temperature, bridge temperature, and pavement conditions are also widely used in winter maintenance.

But weather forecasts alone do not give enough precise data and more online information is needed. That can be acquired from weather stations that are costly to erect and maintain: costs 30,000-40,000 EUR per item, density should be one station per $100 \mathrm{~km}^{2}$ [15]. Different built in sensors for road network monitoring are also a costly solution. Smartphone accelerometers can fulfill the gap of giving sufficiently precise information without significant extra costs.

\section{System design and implementation}

In this section, authors introduce the design and implementation of proposed road winter condition detection system. First is presented the system over-view followed by the design of detection algorithms and elaboration on implementation details. Design is general, not constrained to any particular brand or type of mobile phone; and also power-aware, as hardware such as the screen is only activated when necessary.

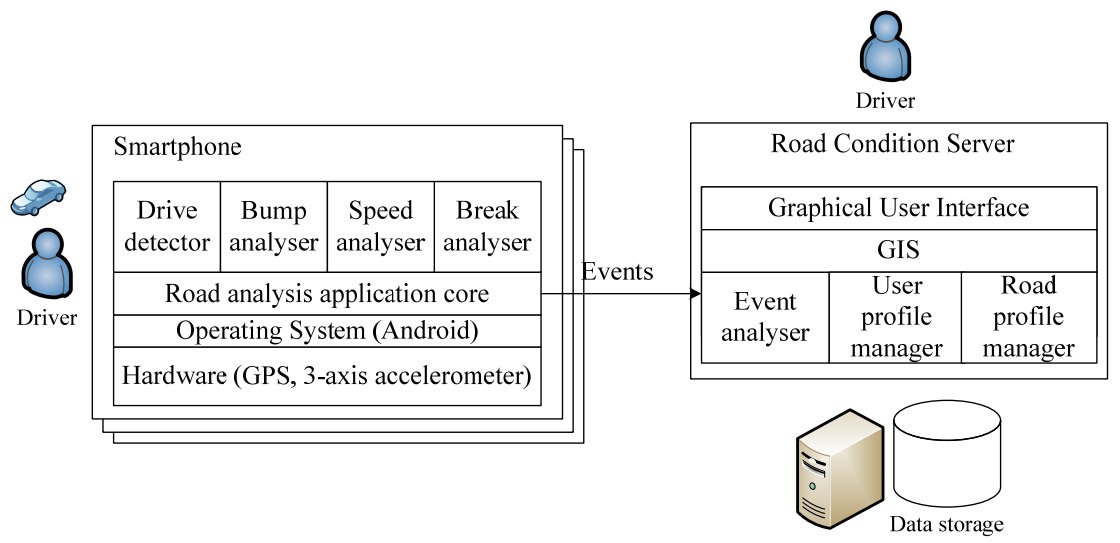

Figure 3: System high-level architecture. 
The conceptual system contains two main components: Road Condition Server and the smartphone (see ). The smartphone application will take care of analysing different sensors and will produce the events towards Road Condition Server. The events are sent over mobile packet data communication channels.

The driver has smartphone. The smartphone hosts special application for road condition monitoring. Applications can be written to record, analyze and upload accelerometer data to a remote server so information about the transportation network can effectively be measured continuously [3].

The application proposed by authors has the following sub-components:

- drive detector,

- road bump analyser,

- $\quad$ speed analyser,

- break analyser.

Drive detector is using accelerometer and GPS speed data to detect if the movement of the smartphone could be caused by moving vehicle. The vehicle movement fact is published to other modules to use it as input.

Road Bump analyser is using the mechanisms familiar with Pothole Patrol concept to detect irregularities in the pavement.

Speed analyser is comparing the speed of the vehicle against thresholds. Passing the threshold generates an event towards backend server.

The events may be classified as:

- $\quad$ irregularity event - produced when the road surface irregularity is detected by the detection algorithm,

- $\quad$ speed event-produced when the speed of the vehicle passes the preconfigured thresholds,

- break event-produced when the accelerometer detects negative acceleration.

The event information is collected by the backend Road Condition Server and analysed further.

\section{Information collection process}

\subsection{Sensor data acquisition}

The road quality data acquisition process is divided into the following main steps: 1) sensor data acquisition, 2) feature extraction, 3) classification, 4) anomaly detection, 5) profile calculation and blacklisting, and 6) information distribution. Steps 1-3 are executed in the smartphone application, steps 4-6 in server side (see ).

Android Operating System based smartphone hardware platform contains several types of sensors that can be categorized as motion, environmental and position sensors, including triple-axis accelerometer, and GPS to capture geographical coordinates and vehicle speed. Other smartphone hardware platforms have similar functionality available.

The accelerometer measures the acceleration in $\mathrm{m} / \mathrm{s}^{2}$ that is applied to a device on all three physical axes ( $\mathrm{x}, \mathrm{y}$, and $\mathrm{z}$ ), including the force of gravity. 
Applying high-pass filter to the accelerator values linearizes the values and gives the acceleration value excluding force of gravity.

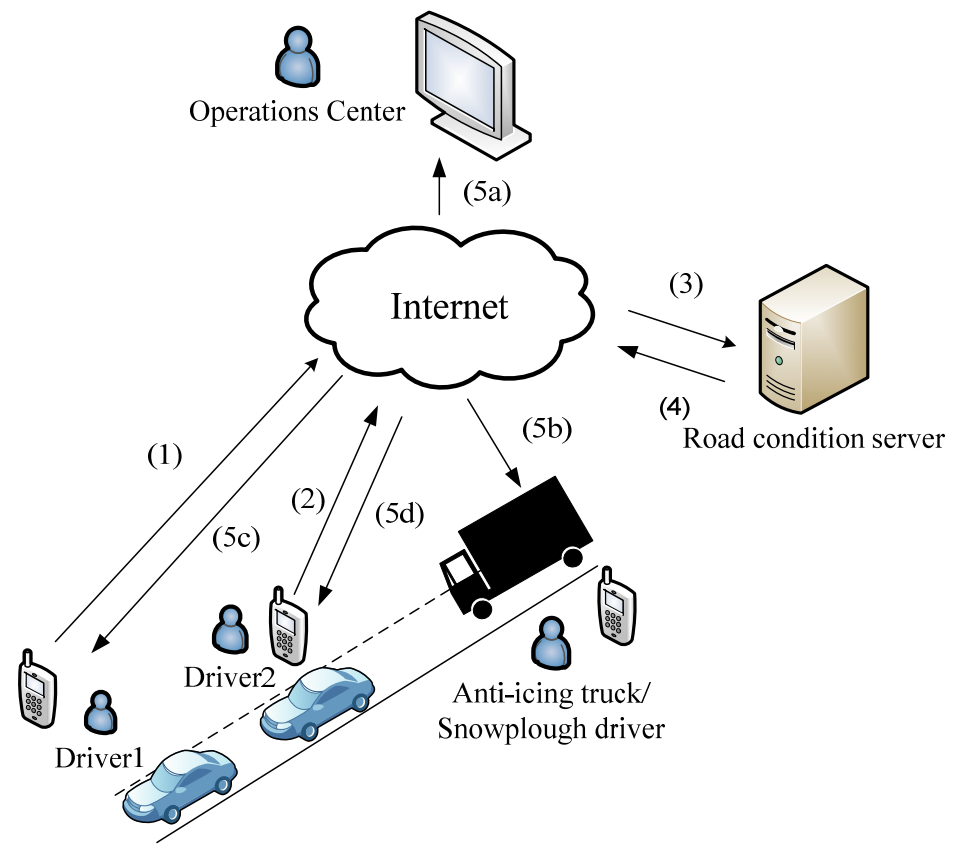

Figure 4: $\quad$ Example scenario.

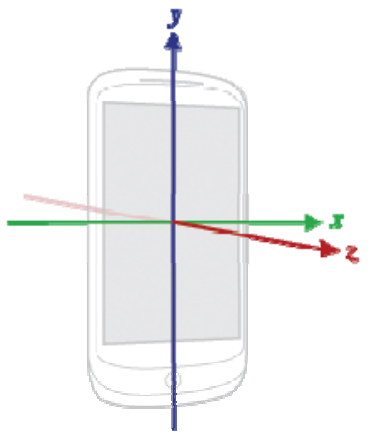

Figure 5: $\quad$ Smartphone accelerometer coordinate system [17].

The accelerometer coordinate-system (see ) is defined relative to the screen of the phone in its default orientation. The axes are not swapped when the device's screen orientation changes. The $\mathrm{x}$ axis is horizontal and points to the right, the $\mathrm{y}$ axis is vertical and points up and the $\mathrm{z}$ axis points towards the outside of the 
front face of the screen. In this system, coordinates behind the screen have negative $\mathrm{z}$ values [16].

The accelerator three-dimensional input signal is merged into one acceleration magnitude by taking the Euclidean magnitude of the three individual values. It can be done since the bump detection algorithm does not require distinction of directional accelerations [18].

The vehicle location and speed is obtained using GPS sensor. Geographic location is sensed at a particular time. A location consists of latitude and longitude, a Coordinated Universal Time (UTC) timestamp, and optionally information on altitude, speed, and bearing.

GPS accuracy is important in pothole detection they need to be properly located and multiple detections combined to report a single pothole. In case of maintenance planning solutions the accuracy is not so important, it is important to know where are the areas in need of maintenance and which are in good condition.

The acceleration magnitude and GPS signal obtained by the phone is noisy. The noise comes from two primary sources: irregular sampling rates and discrete physical sampling of a continuous function. In parallel with the acceleration magnitude and location data the vehicle speed is captured and analysed.

\subsection{Feature extraction and classification}

Dynamically sized sliding window is applied to the acquired data and different features are extracted:

- $\quad$ vehicle speed - minimum, maximum and arithmetic average values in the time window;

- acceleration magnitude - fundamental frequencies, arithmetic average, minimum, maximum value, standard deviation, mean, variance;

- acceleration values for each axis - fundamental frequencies, arithmetic average, minimum, maximum value; standard deviation, mean, variance.

The features are classified and published as events from the smartphone to the server when enough evidence is found using Naïve Bayes classifier. On server side another more resource intensive classification algorithm will continue evaluation of the events.

The real time event collection feed (steps $1 \ldots 3$ in ) is evaluated on server side based on the event class, location, driver profile, weather forecast and road weather station readings, collection time, and closest data in time when the road section was clean. Another sliding time window of an event is dynamic and based on the amount of events in time interval on that particular road. Data processing anomalies are detected during the process and logged for learning purposes.

For example: first driver smartphone application classifies an event. The event data together with metadata is passed on through Internet (using mobile data communication technology) to the backend Road Condition Server (step 1). The second driver detects an event approximately in the same location (step 2) and passes the data to server. The real time event collection feed (step 3) is 
evaluated on server side based on the event class, location, driver profile, weather forecast and road weather station readings, and collection time.

The event is sent out from the server (step 4) and distributed to interested parties (step 5). The time window of an event is dynamic and based on the amount of events in hour on that particular road. After successful evaluation of the series of events, the road profile (and the map) is updated with the combined event information. Also the user profile will be updated with higher trustworthiness rank.

A key to the system success is making it possible to have communication between any information provider and information consumer without the need for complex integration work. Access to the system is controlled via security levels - an information consumer is only able to consume the data on the level to which it has been provided access, e.g. some users may only have access to aggregated and pre-processed data, while other users have access to data at the sensor level. The data access mechanisms stay the same, no matter what level access or to what data is requested and granted.

\section{Conclusions and further research}

Over the past decades attention has been turned towards improvements in winter highway maintenance operations to accomplish three critical goals: reducing costs, increasing safety and minimizing environmental impacts. In this article the authors have proposed a new approach to winter road maintenance improvement for transportation agencies. It is especially useful tool in urban areas with extensive street networks and high population.

The proposed solution that gives information about road roughness and maintenance needs in winter time is a further development of existing systems that use smartphone accelerometers in characterizing pavement condition. Participatory sensing using smartphone accelerometers for data collection is proposed due to its low cost, large number of road users and real time coverage.

The use of participatory sensing is an easy and operative tool of real time monitoring the condition of roads in urban areas. The simultaneous and online information gives maintenance companies a database to be efficient. An advantage is given to use limited maintenance funds where only and exactly where servicing is needed increasing safety, environmental responsiveness and helps to avoid excess wasting of resources.

The proposed solution measures road quality during the year, forming a database of the state of the road network. With the yearly advent of winter weather the same description of road network is the base dataset starting to gather new information about weather caused abnormalities. Both ports of the applications can be implemented as parts of Performance Measurement Systems (PMS) for roads and authors have planned addressing this issue during further research.

To determine the potential of smartphones in transport monitoring and additional applications authors are considering a number of successive trials and further research. The work described in this paper is part of a larger effort to 
mine, collect and systemize online sensor data from wireless devices. Authors believe that information acquired by mobile sensing provides tremendous opportunities for data mining and we intend to leverage our smartphone-based data collection platform to the fullest extent possible.

Wider objective of further research is: develop a country-wide road monitoring system that collects data about parameters of interest and is able to provide information to any interested party that is authorized to view the information. Potential beneficiaries of this system are:

- $\quad$ society as whole;

- government and local road administration authorities;

- $\quad$ road maintenance and construction companies;

- $\quad$ design and research institutions;

- transportation and forwarding companies;

- internal and external security forces (police, customs, border guard authorities, defence forces), etc.

Present research shows that sensors in the smartphoneplatform could support and substitute in some areas costly weather stations leaving their density optimal. The solution gives information to route maintenance equipment to the streets that require servicing and avoid unnecessary travels.

\section{References}

[1] Yearbook 2011. Estonian Road Department: Tallinn, 69 pp., 2012 (in Estonian).

[2] Ye, Z., Strong, C., Fay, L. and Shi, X. Cost Benefits of Weather Information for Winter Road Maintenance. Western Transportation Institute: Bozeman, 136 pp., 2009.

[3] Parry, T., Dawson, A., Byrne, M. and Isola, R. Collecting transport information using Smartphones apps. Transportation Professional, December, pp. 28-29, 2011.

[4] Paterson, W.D.O. and Watanatada, T. Relationships between Vehicle Speed, Ride Quality, and Road Roughness. Measuring road roughness and its effects on user cost and comfort, eds. T.D. Gillespie and M. Sayers, ASTM: Baltimore, pp. 89-110, 1985.

[5] Kertesz, I., Lovas, T. and Barsi, A. Measurement of road roughness by lowcost photogrammetric system. The $5^{\text {th }}$ International Symposium on Mobile Mapping Technology (MMT'07), Padua, 4 pp., 2007, http://www.cirgeo. unipd.it/cirgeo/convegni/mmt2007/proceedings/.

[6] Eriksson, J., Girod, L., Hull, B., Newton, R., Madden, S. and Balakrishnan, H. The Pothole Patrol: Using a Mobile Sensor Network for Road Surface Monitoring. Proc. of the $6^{\text {th }}$ int'l. conf. on Mobile systems, applications, and services MobiSys. ACM: New York, 2008.

[7] Mednis, A., Strazdins, G., Zviedris, R., Kanonirs, G. and Selavo, L. Real Time Pothole Detection using Android Smartphones with Accelerometers. Int. Conf. on Distributed Computing in Sensor Systems and Workshops (DCOSS) 2011, http://strazdins.lv/papers/mednis2011androidpotholes.pdf. 
[8] Mohan, P., Padmanabhan, V.N. and Ramjee, R. Nericell: rich monitoring of road and traffic conditions using mobile smartphones. Proc. of the $6^{\text {th }}$ conf. on Embedded network sensor systems SenSys. ACM: New York, 2008.

[9] Perttunen, M., Mazhelis, O., Cong, F., Kauppila, M., Leppänen, T., Kantola, J., Collin, J., Pirttikangas, S., Haverinen, J., Ristaniemi, T. and Riekki, J. Distributed Road Surface Condition Monitoring Using Mobile Phones. Lecture Notes in Computer Science, 6905, pp. 64-78, 2011.

[10] González, A., O'Brien, E.J., Li, Y. and Cashell, K. The use of vehicle acceleration measurements to estimate road roughness. Vehicle System Dynamics, 46(6), pp. 483-499, 2008.

[11] Strazdins, G., Mednis, A., Kanonirs, G., Zviedris, R. and Selavo, L. Towards Vehicular Sensor Networks with Android Smartphones for Road Surface Monitoring. The $2^{\text {nd }}$ Int'l. Workshop on Networks of Cooperating Objects CONET 2011, http://strazdins.lv/papers/strazdins2011android potholes.pdf.

[12] Nagase, T., Hasegawa, D. and Araki, T. SD-IMAS: a New Slip Detection System design for a Vehicle using an Induction Magnetometer and an Accelerometer. WSEAS Transactions on Circuits, 1(2), pp. 86-89, 2003.

[13] Saarenketo, T. Monitoring low volume roads. Roadex III Northern Periphery: Luleå, 28 pp., 2006.

[14] Kõrbe Kaare, K. and Koppel, O. Improving the Road Construction Supply Chain by Developing a National Level Performance Measurement System: the Case of Estonia. World Academy of Science, Engineering and Technology, 62, pp. 276-282, 2012.

[15] Metlitski, S. Personal communication, 23 April 2012, Head of ITS Department, TECER, Ltd. (Estonia).

[16] Sensors. Android Developers Online, http://developer.android.com/guide/ topics/sensors/index.html.

[17] Schirmer, M. and Höfpner, H. Smartphone Hardware Sensors. Mobile Media Group, http://www.uni-weimar.de/medien/wiki/images/ Zeitmaschinen-smartphonesensors.pdf.

[18] Das, S., Green, L., Perez, B. and Murphy, M. Detecting User Activities using the Accelerometer on Android Smartphones. University of California: Santa Cruz, 11 pp., 2010. 